behaved as clinographs, and components of vertical and horizontal movements have not been faithfully recorded. Mr. Imamura gives results relating to the speeds at which earthquake motion has been propagated over the Tokio area. At four stations, from 2 to 10 kilometres apart, and connected by telegraph, seismographs were arranged each of which gave an open diagram on a surface marked by time intervals sent from the Seismological Institute. From the differences in time at which the same wave was recorded at different stations, the speed of that wave was determined. The surface velocity arrived at is that $\mathrm{V}=3^{\circ} 2 \mathrm{~S}+0^{\circ} 05$ kilometres per second, but as to whether different waves in the same earthquake travel with the same speed, which we think is not the case, we are left in darkness. In a paper on after shocks, Prof. Omori shows that the expected or calculated number of such settlements for a given period closely accords with observation. By maps and diagrams he also shows the space distribution of after shocks, there being, as might be expected, fewer of these disturbances recorded at places distant from a focus than at those conparatively near.

In a paper on pendulum seismographs (Bolletino deil: Societa Sismologia Italiana, vol. vii.) Dr. Agamennone eulogises the work of the Seismological Society of Japan for the revolutionary effect it has had upon seismometry. FCr 130 years prior to the existence of this Society the crdinary instrument employed to record earthquakes was a vertical pendulum. Subsequently horizontal pendulums ivere used, and seismometers took the place of seismoscopes. The results which have been achieved by the new types of instruments as recorders of movements that can be felt are well known, but the value of the records relating to earthqualie motion which has radiated to great distances, beyond timing certain phases of motion, is very doubtful.

The horizontal pendulum largely used in Germany, Austria and Russia, when recording on slowly moving photegraphic paper, has been referred to as a species of delicate seismoscope. To some extent this may be true, but yet it records certain phases of motion, and frequently picks up small disturbances which are not recorded by more cumbrcus forms of apparatus. In his paper Dr. Agamennone gives three seismograms obtained from ordinary pendulums, respectively 16,8 and 3 metres in length, written upon surfaces moving at rates of from 26 to 40 metres per hour. Such seismograms show the earthquake vikrations superimposed upon those due to the swinging of the pendulums. For recording earthquakes at great distances from their origins, Dr. Ömori not only advocates the use of quickly moving surfaces, but that a horizontal type of pendulum should be employed the period of which should be long. On account of the diurnal and other wander-

ings of such a pendulum, for most foundations this period is, however, limited to about thirty seconds.

Other seismologists have also suggestions, and when it is remembered that in a given earthquake continuing for several hours there are groups of waves with periods varying between a fraction of a second and a minute, it is easy to imagine that this should be the case.

In short, so far as the recording of the period and amplitude of unfelt earthquakes are concerned, seismologists are not in step, and until opinions are less divided, which is not likely to be the case until more experiments have been made, to impose a type of instrument upon the world for the purposes specified seems likely to prove detrimental to seismometrical inquiry.

In the last issue of the Bollettino of the Seismological Society of Italy, vol. viii. No. 6, M. Alippi gives a short paper on subterranean sounds. 'The mysterious detonations heard in Holland and on the shores of the North Sea known as mist poeffers are atmospheric phenomena. These, which may be the same as the sounds called barisal guns, must not be confounded with sounds originating in the earth. These latter, which by no means necessarily accompany earthquakes, are in Italy referred to as rombo, bombio, bonniti and other expressions clearly of onomatopoetic origin.

The remaining pages of the number contain the seismic register of Italy for March and April, yor. The late appearance of this register is on account of the fact that it practically includes all observations made upon earthquakes which have been recorded in the Italian peninsula, and as these include world-shaking disturbances, the collection of material from foreign ccuntries occupied considerable time.

As this publication stands facile princeps amongst its kind, Prof. Pietro Tacchini and his staff are to be congratulated on their useful work.

\section{THE NEW BIOLOGICAL STATION AT PORT ERIN.}

THE sixleenth annual report of the Liverpool Marine Biology Committee, ${ }^{1}$ which records the completion and occupation of the new buildings at Purt Erin, opens a fresh period in the history of this Committee, which was constituted in March, i 885 , at a public gathering of the local naturalists from Liverpool, Manchester. Southport, Chester and the neighbour. hood, sumnoned by Prof. Herdman for the purpose. The declared objects were " to investigate the marine fauna and fora (and any related subject such as submarine geology and the

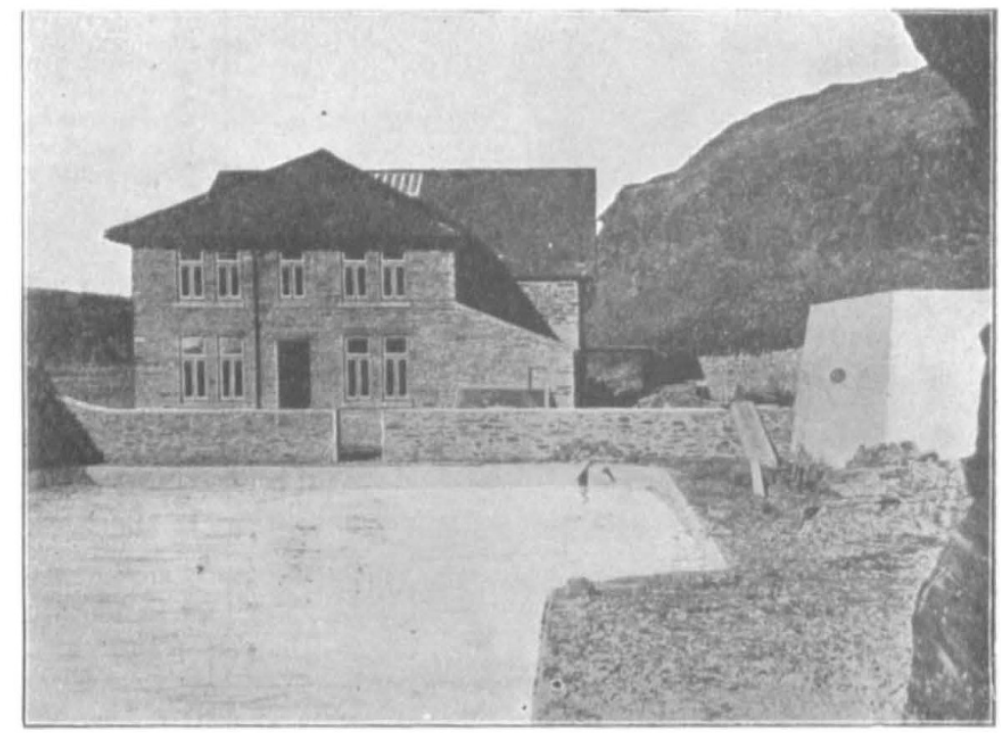

FIc. 1.-Western End of Stati sn, showing Spawning Pond and Hatchery Entrance. No. 1742 , vOL. 67]

physical condition of the water) of Liverpool Bay and the neighbouring parts of the Irish Sea, and, if practicable, to establish and maintain a biological station on some convenient part of the coast." These ends have been kept steadily in view for the last seventeen years. At an early stage of the investigations, in 1887 , the Committee established a small biological station on Paffin Island, off the north $c f$ ast of Anglesey, and during the next five years this laboratory was kept up, and dredging and other exploring expeditions were carried on from it.

Then the centre of the Committee's field work was transferred from Anglesey to the Isle of Man-" from the Mona of Tacitus to the Mona of Cæsar." Here a small biological station was built on the northern side of Port Erin Bay and was formally opened for work on June 4, 1892, by Sir Spencer Walpole, then Governor of the island. Notices of the work carried on in this laboratory and of the dredging expeditions in the Irish Sea 
during the last ten years have appeared from time to time in the pages of NATURE.

The alliance between a committee appointed by the Manx Government and the Liverpool Committee, which has now resulted in the provision of a much larger biological station on a better site at the southern side of Port Erin Bay, had its origin in the sea-fisheries work carried out on an experimental scale in the old station for the purpose of obtaining information for the Lancashire Sea-fisheries Committee.

The details of the arrangement concluded between the Manx and Liverpool committees are given in the report. It may suffice to say that the two committees have evidently worked most harmoniously together, and will no doubt continue to cooperate cordially and usefully. Of the three departments in the institution, the laboratory block will be wholly under the control of the Liverpool Committee, the fisheries block will belong solely to the Manx Committee, and the aquarium in the centre will be managed as a joint concern in the interests of both the scientific and economic work. The curator of the old biological station (Mr. H. C. Chadwick) has become curator of the whole institution, with a practical fisherman assistant under him, and the hon. director and chairman of the Liverpool Committee (Prof. Herdman) is recognised as being director also of the whole. This should secure unity of aim and

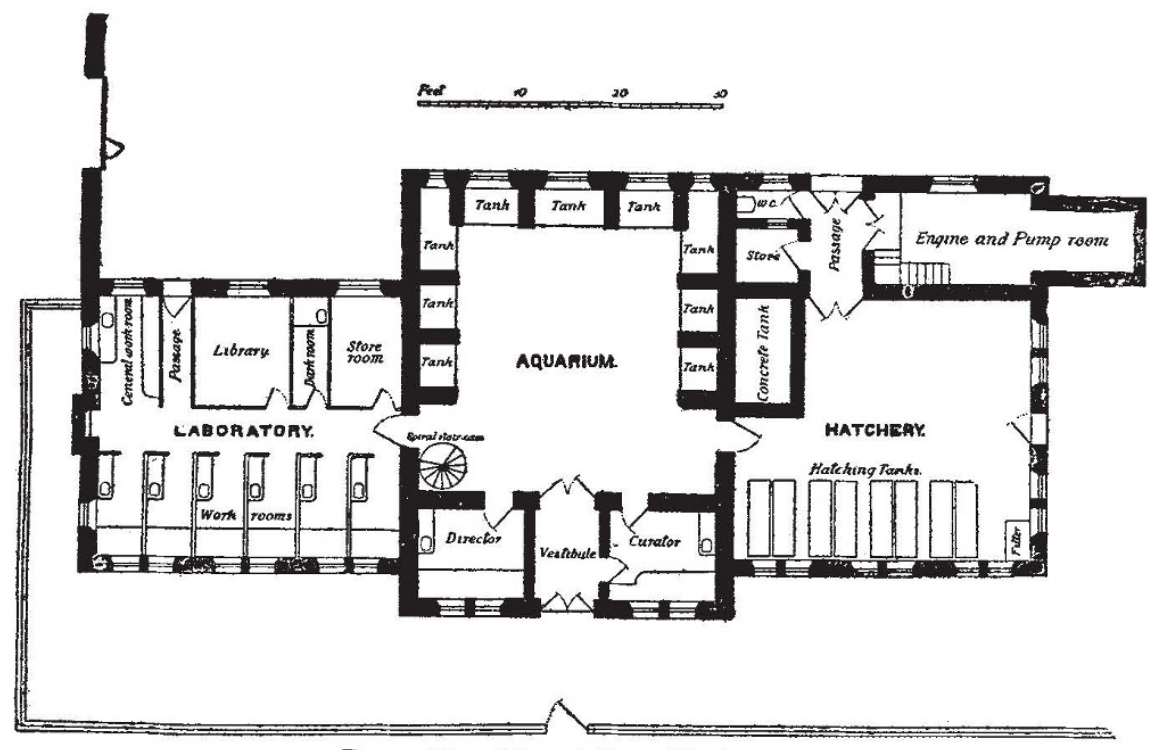

Fig. 2.-Plan of Ground Floor of Station.

economy of working, and will result in the various departments being mutually helpful. The fishery work will be instructive to the scientific students, and the investigations in the laboratory and experiments in the aquarium will be useful in connection with fishery problems. The aquarium, which, with its museum of local marine animals and plants in the gallery, occupies the large central block of the building, is the only part open to the public, and will, it is hoped, be useful alike (I) to the scientific workers in the laboratory, (2) for experiments and observations bearing on fishery questions and practice, and (3) as an educational influence which will be appreciated by the mpre intelligent visitors, and may, it is hoped, be taken advantage of by local schools for instruction in nature-study.

The station is a plain but substantial two.storied stone building of nearly 100 feet in length by more than 40 feet in breadth, with a light railing in front and a large yard, enclosed by a wall, behind. At the western end (Fig. I) is a large pond excavated in the rock, measuring about 90 feet in length, nearly 50 feet in breadth, varying from 3 to 10 feet in depth, and capable of containing about 130,000 gallons of sea-water.

The plan (Fig. 2) shows the division of the building into a central aquarium and lateral laboratory and fisheries wings, and gives the arrangement of the rooms on the ground floor. The upper storey has a broad gallery round the aquarium and large laboratories in the wings. Of the six small workxooms to the

NO, I 742, VOL. 67$]$ front on the ground floor, four are now permanently engaged by universities, leaving two still vacant. The junior laboratory on the floor above, it is announced, will be occupied by a class for school teachers during the Easter vacation.

For the information of students and other naturalists who may propose to visit the new biological station, it may be wel to state that Port Erin is at the south-west end of the Isle of Man and occupies a fairly central position in the Irish Sea, being about 30 miles from Ireland, 33 from Scotland, 40 from Wales and 45 or so from England. The bay faces nearly due west, has sand at the end, and is bounded by precipitous cliffs both to the north and south. From its position and the shape of the land, Port Erin has within a distance of a couple of miles in three directions-to Fleshwick Bay, to the Calf Island and to Port St. Mary - a long and varied coast line with a number of small bays furnishing good collecting ground and shallow water for dredging. Two of these bays, Port Erin and Port St. Mary, have harbours with sailing boats and face in nearly opposite directions, so that in most winds one or other is sheltered and has a quiet sea.

The rich fauna round the Calf Island and off Spanish Head is within easy reach; while at a distance of three to four miles from the biological station are depths of 20 to 30 fathoms, and at 14 miles 60 to 70 fathoms depth is found.

The aquarium of the new station was opened to the public in the middle of August, and in October more than six hundred visitors had already paid for admission.

The report from which these remarks are extracted gives also an account of the scientific work undertaken by the Committee during the last year and records many additions to the local marine fauna, chiefly amongst the microscopic crustaceans worked out by Mr. A. Scott.

The report points out, finally, that while the change to the new building is advan. tageous in giving better accommodation and larger op portunities, it also gives increased labour and responsibility and in no way relieves the Liverpool Marine Biology Committee of financial burdens, The Committee retains its identity and constitution exactly as before, and the subscriptions from those who are kindly supporting the work will be required fully as much in the new building as they were in the old. The Manx Government subsidy will be entirely applied to the economic work in connection with the local sea-fisheries and will not be available for the purely scientific work of the biological station.

\section{BOTANICAL NOTES.}

UNDER the title of "Vegetationsbilder," Messrs. Gustav Fischer, of Jena, announce a series of photographic reproductions which will illustrate characteristic types of vegetation. Each part, consisting of six plates and the explanatory text, will be devoted to one region or formation, and will be complete in itself. The photographs were taken by Drs. Schenck and Karsten, who undertake the arrangement of the work. The first and second parts now received depict the scenery of South Brazil and of the Malay Archipelago; other parts of the eight projected will illustrate botanical features of South-West Africa, Mexico, tropical economic plants, \&c. The photographs are reproduced nearly full-plate size, and recall the illustrations of Schimper's "Pflanzengeographie," which is published by the same firm. 